\title{
The Distinction Between Equality in Moral Status and Deserving Equal Consideration
}

\author{
David DeGrazia \\ George Washington University
}

Editors' Note: The following paper by Professor DeGrazia, the commentary on it by Professor Squadrito, and DeGrazia's response were presented at the Pacific Division meetings of the Society for the Study of Ethics and Animals, held in Los Angeles, California, March, 1990.

\section{Introduction}

Passions tend to run high in ethical debates concerning animals, not only among laypersons and in political arenas, but also in the normally cool chambers of academic philosophy. Objectivity and care, though indispensable for understanding differing positions and their supporting arguments, often seem in short supply. As a result, distinct issues are confused while arguments are misunderstood and then misrepresented in counterarguments.

This essay concerns two normative concepts whose conflation in animal ethics debates easily leads to intellectual mischief: (1) equality in moral status, and (2) one's interests' having moral weight equal to the identical interests of others. (2), which is difficult to formulate precisely without awkwardness, might also be put in this way: one's interests' deserving equal consideration to the identical interests of others. After distinguishing and clarifying these concepts, I present a preliminary case for the thesis that animals are unequal in moral status - though their interests should be given equal consideration. In making my case I note some general implications for the use of nonhuman animals (hereafter, simply "animals") in research.

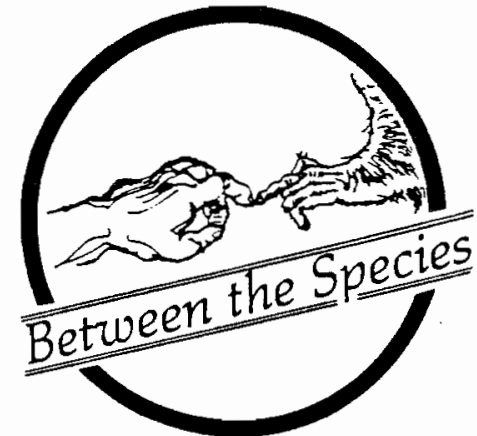

Let me begin by presenting a couple of examples of the confusions to which I refer. First, in a widely read article, Katie McCabe, a journalist, makes a seemingly innocuous attribution: "Singer...argues that all sentient beings have equal moral status...." Once equal moral status and equal consideration are distinguished, given a general familiarity with Singer's work, it becomes clear that this attribution is false, or at least very uncertain-though Singer unequivocally argues for equal consideration.

These words from philosopher Carl Cohen will serve as a starting point for disentangling these concepts (providing a second example):

The first error [of animal activists] is the assumption, often explicitly defended, that all sentient animals have equal moral status. ${ }^{2}$ Between a dog and a human being, according to this view, there is no moral difference; hence the pains suffered by dogs must be weighed no differently from the pains suffered by humans. ${ }^{3}$

Here Cohen confuses ${ }^{4}$ these two claims: (1) that two individuals, say a human and a chicken, have equal moral standing or status (to be defined below), and (2) that an interest had by one being, say the interest a human has in avoiding suffering, has equal moral weight with the identical interest had by another being, e.g.,

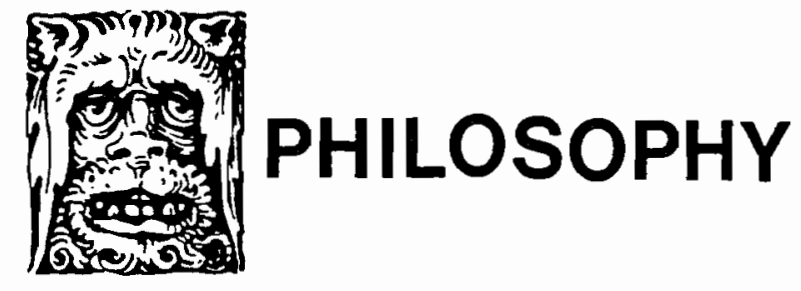


the chicken. Let us first elucidate the simpler notion of the equal consideration of interests.

\section{Equal Consideration of Identical Interests}

I begin with two premises that I will not defend in this essay: (1) some animals have interests, ${ }^{5}$ and (2) their interests have some moral weight. Given this, we must consider whether identical interests count equally, i.e., whether they have equal moral weight. The principle of equal consideration of interests ("principle of equal consideration," for short) says that they do. Obviously, this issue is of the utmost importance for animal ethics. If the interest that, say, a cat has in $X$ (where $X$ is a particular object of an interest, e.g., freedom) does not have as much moral weight as the interest a human has in $\mathrm{X}$, perhaps it has very little weight. If all animal interests had very little weight compared to the identical interests of humans, this would vindicate the ways animals have traditionally been regarded in our society. But if the principle of equal consideration is true (or otherwise worthy of acceptance), then, obviously, many of our animalexploiting institutions are morally unjustified.

It has been argued by a number of philosophers, including Singer and Hare, that equal consideration is a formal requirement of morality or, in other words, that the concept of morality, or the logic of moral language, includes this requirement. ${ }^{6}$ This is almost certainly false. Would a putatively moral system that stipulated that the interests of everyone counted equally, except for Jesus', which counted twice as much as the others, for that reason fail to be a moral system? On the other hand, not counting identical interests equally seems in need of justification. It is appropriate to ask why so-and-so's interests should count more than those of others. If the interests one being has in $\mathrm{X}$ do not have the same moral weight as the interests another being has in $\mathrm{X}$, there must be a morally relevant difference between them.

This is a consequence of the principle of universalizability. I assume a formulation of this principle that I think least contentious and clearly reasonable as a constraint on moral reasoning: If $A$ judges that $P$ in circumstances $\mathrm{C}, \mathrm{A}$ must judge that $\mathrm{P}$ in relevantly similar circumstances (ones relevantly similar to $\mathrm{C}$ ). This principle has the following implication: If $A$ judges that the interests of being $B$ have weight $W, A$ must judge that the interests of beings relevantly similar to $B$ have
$W^{7}$ Clearly a great deal of weight falls on what counts as "relevantly similar." Or-since another way to state the principle of universalizability is to say that, for A to make two incompatible judgments in two different cases, the second case must bear a relevant difference from the first - the weight may be seen to fall on what counts as a "relevant difference."

Therefore, while it cannot be stated dogmatically that the concept of morality includes the requirement that all identical interests count equally (as Singer and Hare would have it), given the principle of universalizability, the onus of proof falls on the inegalitarian, for she must identify the relevant difference between the two beings that justifies making different moral judgments with respect to them.

\section{Equality of Moral Status}

Let us turn now to equal moral status, a somewhat vague but commonly employed notion. $A$ and $B$ have equal moral status, in the relevant sense, if and only if they deserve equal treatment in a particular sense of "equal" that is difficult to define but fairly easy to grasp through examples. First, let us elucidate equal treatment with an example. It might be said that dogs deserve dog food while cats deserve cat food. To give dogs and cats the food they deserve is to treat them unequally in one sense because it is to give them different kinds of food, but this is not the sense I am after. In the relevant sense, to give cats cat food and dogs dog food is to treat them equally because it is in their interests to be fed food appropriate for their species, and to feed them in this way is to affect the only interest at stake equally. It is compatible with the claim that dogs and cats have equal moral standing to judge that dogs deserve dog food and cats deserve cat food. It is not compatible with this claim to judge that dogs deserve dog food and cats deserve no food, for this judgment implies that the two creatures deserve unequal treatment (in the relevant sense).

If two beings have equal moral status if and only if they deserve equal treatment, what is moral status itself? Moral status is the degree (relative to other beings) of moral resistance to having one's interests-especially one's most important interests $-t h w a r t e d$. Suppose that whenever it is morally imperative that either A or B die, suffer, endure a severe restriction of freedom, or have some other important interest thwarted, it is A whose interests, morally, should be thwarted. Then B has greater moral status than $\mathrm{A}$, because the moral 
resistance of B's most important interests against being thwarted, is greater than that of A's interests. The imaginary case of A and B would be a very clear example of one being's having greater moral status than another.

But for two beings to differ in moral status, it need not be the case that one's interests always have stronger moral resistance to being thwarted than another's. I am convinced that actual differences in moral status are more subtle than that. But even if two beings' interests have equal moral resistance to being thwarted, except for one very important interest-with respect to which one's interest is always (or almost always) rightly sacrificed instead of the other's identical interest-it is correct to say that they differ in moral status (to that degree).

The essential idea is simply this: If we consider a broad range of cases in which the important interests of either A or B must (morally) be thwarted, and A loses out in some of these cases but B does not (or rarely does), then $A$ is more sacrificeable in an important sense-in this sense A has lower moral status. As an illustration, we tend to think that trout have lower moral status than humans; we tend to believe that there are cases in which it would be right to sacrifice interests (e.g., life, freedom, experiential welfare ${ }^{8}$ ) of one rather than the other, and that it is usually or always the trout's interests that are rightly sacrificed.

\section{Equal Consideration and Unequal Moral Status}

I will now argue that, even if the principle of equal consideration is true, there is good reason to believe that animals differ in moral status. (A successful argument will, of course, show that the two concepts are distinct.) I begin with the assumption that there are no arguments that meet the onus of proof-established by the principle of universalizability-on the person who denies the principle of equal consideration. This assumption notwithstanding, I think an examination of interests shared by animals and humans suggests that humans have greater moral status than animals. (Assume from now on that by "humans" I mean normal adult humans.) ${ }^{9}$

In my view animals (that have interests at all) share these three fundamental objects of interests with humans: (1) a favorable experiential welfare ${ }^{10}$; (2) the freedom (lack of external constraints) necessary to do what they desire to do; and (3) life or remaining alive. ${ }^{11}$
Let us look at these in turn to see if differences in moral status appear with respect to any of them.

First, I believe that there are insufficient grounds for arguing that equal consideration of experiential welfare interests reveals differences in moral status. The picture is complicated. In the light of certain factors, equal consideration seems to favor, for example, performing painful experiments on a cat as opposed to a human (if either is to be used and the human does not volunteer): The suffering caused to humans who are terrified about being conscripted for the research, the humans' anticipatory dread if they are kidnapped, and so on-none of which a cat would experience. At the same time, other considerations seem to favor using a human. For example, the fact that an experiment will last only a few days and will not involve killing research subjects (if that is the case) can be explained to a human, not to a cat, so that a cat might suffer more fright during the research. ${ }^{12}$ In the light of such mixed considerations I am unprepared to assert that differences in moral status appear with respect to experiential welfare.

However, I think that differences in moral status do begin to appear when we consider the interest of freedom. Because external constraints thwart an individual's freedom-interest by preventing her from doing what she wants, it may be said that they thwart this interest to the extent that they prevent her from doing what she wants. And this is a function of the range and nature of things an individual wants to do. The point is that, if, e.g., a dog and a human were kept captive for a number of days for the purposes of an experiment, no matter how humanely they were treated, such captivity would generally (not always) do more violence to a human's plans than it would to the totality of things the dog would want to do. ${ }^{13}$ I ask the sceptical reader to consider all the things she wants to do in the next, say, five days and where she would have to go to do them. This gives us, generally, one reason-which, to my knowledge, has been overlooked until now-for preferring the use of animals over humans in (freedomrestricting) research. ${ }^{14}$

Differences in moral status appear most vividly, I think, with respect to life, but this is also the interest about which it is most difficult to say anything with certainty. ${ }^{15}$ A good way to start the analysis is to ask why death is a harm, or, equivalently, why life is valuable. People seem to use different language to describe the same intuitive idea. R. G. Frey holds that life is valuable because of its riches and that the value 
of a given life is a function of its riches. For this reason he thinks that human life - which is characterized by deep personal relations, enjoyments of myriad kinds from hedonistic ones to the most refined, and autonomously pursuing lifeplans_-simply overwhelms in value the life of an animal. ${ }^{16}$ Tom Regan argues that death is a harm because it forecloses all opportunities an individual has for obtaining the satisfactions available to members of one's species, and more opportunities are closed off in the case of a human than in the case of a dog. ${ }^{17}$ I make essentially the same point as Frey and Regan by asserting that the death of a human thwarts more interests, and more very important or central ${ }^{18}$ interests, than the death of an animal, so that the former is the greater harm. ${ }^{19}$ It really is difficult to believe that the painless killing of a human is not normally more destructive of something objectively valuable than the painless killing of an animal. This intuition persists, I think, even when we consider the fact that whatever a hamster's life involves is all the hamster has.

If the preceding reflections are sound, differences in moral status appear with respect to life-interests. Applying the principle of equal consideration, it is worse, other things being equal, to kill a human than to kill an animal. That gives us one good reason to prefer the use of animals over humans in experiments that result in the research subject's death, if such experiments are to be done at all. Thus, in freedom-restricting research that ends in the subject's death, there are two prima facie reasons to prefer the use of animals over humans: giving identical interests equal weight, a particular restriction of freedom is generally more harmful to humans than to nonhumans, while death is similarly a greater harm, in most cases, to humans than to nonhumans. If this is right, then animals are, after all, somewhat more sacrificeable than humans, though it may be that there are very few cases in which anyone's interests may justifiably be thwarted in research. ${ }^{20}$ In this light, we may acknowledge that there are differences in moral status between humans and nonhumans (and, no doubt, among different animals). The crucial point to recognize is that this thesis is perfectly compatible with the principle of equal consideration.

As a concluding comment, those unsympathetic to the animal welfare movement had better get straight which thesis they are attacking. If they are attacking the principle of equal consideration, they have a substantial burden of proof to meet; if they are attacking the thesis that all animals (that have interests) have equal moral status, their target is made of straw. If, like Cohen, they are attacking both theses simultaneously without distinguishing them, they are confused and are lowering the quality of animal ethics debates.

\section{Notes}

1 "Who Will Live, Who Will Die?," The Washingtonian (August 1986, vol. 21, no. 11).

2 For the record, I know of no philosopher who explicitly defends this thesis.

3 "The Case for the Use of Animals in Biomedical Research," The New England Journal of Medicine 315, no. 14 (Oct. 2, 1986), p. 867.

${ }^{4} \mathrm{He}$ either identifies these two claims or thinks that first entails the second. Either way, there is a misunderstanding.

5 I will not develop an analysis of "interest" here, though I give this topic extensive treatment in my dissertation, "Interests, Intuition, and Moral Status" (Georgetown University, not yet printed). For the purposes of this essay, let us assume that Regan's analysis into preference-interests and welfare-interests is roughly correct. So when I assert that an animal has a given interest, it may be assumed that $I$ think it falls under one or both of these categories.

${ }^{6}$ Singer makes this argument in Practical Ethics (Cambridge: Cambridge University Press, 1979), pp. 10-11.

${ }^{7}$ I assume that $A$ judges that the weight of a being's interests remains constant over time. Thus the "circumstances" relevant here, the only ones that might change from one case to the other, are what beings are under consideration. So a relevant difference would be a difference between the beings.

\footnotetext{
${ }^{8}$ I believe the claim that trout have these interests can be defended with a combination of philosophical and empirical arguments. (I argue for the thesis that all vertebrates have these interests in ch. 4 of my dissertation, "Interests, Intuition, and Moral Status.") Anyone who is sceptical might substitute the "lowest" animal she believes capable of suffering, who at least will be believed to have experiential welfare interests. I suspect the conclusion will remain plausible after the substitution.

${ }^{9} \mathrm{I}$ also think differences in moral status exist among (nonhuman) animals, but, for reasons of space, I will not defend this thesis.
} 
10 This is meant to include not having a very bad experiential welfare, so that "a favorable experiential welfare" includes the avoidance of great suffering-although this is sometimes possible only by way of death.

${ }^{11}$ Obviously, as note 10 suggests, this last interest can be extinguished in certain circumstances, for instance, when remaining alive entails intense and prolonged suffering. Less obviously, freedom and experiential welfare can, under pressure, give way as interests. External constraints may be needed for protection from death, injury, or other harm, while suffering may have to be endured to stay alive or to retain one's freedom.

${ }^{12}$ Both kinds of consideration are noted by Singer, Animal Liberation (New York: New York Review: distributed by Random House, 1975), pp. 17-18.

${ }^{13}$ This is only generally true because some humans (e.g., the very old, the retarded) do not always have plans that are so badly thwarted by captivity, while some animals (e.g., birds) may be almost completely frustrated, in terms of what they want to do, by captivity.

${ }^{14}$ Of course, the research we are primarily, if not exclusively, concerned with is freedom-restricting. (Research that does not restrict freedom includes field research and statistical studies based on already obtained data.)

${ }^{15}$ Although I speak of the interests different animals have in life, making it sound as if the same interest were at stake, the relevant interests are not identical. A cat has an interest in continuing to live a cat's existence, while a human has an interest in continuing to live a human existence. That is why it makes sense to say (and, I think, is true) that death takes away things of different value when it takes away the lives of cats and of humans. In this respect, life differs from suffering. The intrinsic "awfulness" of suffering is such that a given intensity and duration of suffering (including unpleasant emotional experiences, which can arise as responses to more sensation-related suffering) is equally bad, no matter who the subject is. In other words, suffering is suffering.

16 "Animal Parts, Human Wholes: On the Use of Animals as a Source of Organs for Human Transplants," Biomedical Ethics Reviews 1987, ed. James M. Humber and Robert F. Almeder (Clifton, New Jersey: Humana Press, 1987).

${ }^{17}$ The Case for Animal Rights (Berkeley: University of Califomia Press, 1983), p. 324.

${ }^{18}$ Assuming, again (see note 5), that the analysis of interests into preference-interests and welfare-interests is roughly correct, we might conveniently say that the former concern what we want, while the latter concern what we need. An interest, then, is central to the extent that it figures prominently in the total system of what we want and need. My desire to become a contributing philosopher is very central to my overall plans; my desire to have grapefruit juice when I get home is not. My need for food in the next week is very central; my need for a lot of exercise in the same time period is less so.

${ }^{19} \mathrm{By}$ "harm" I mean a thwarting of interests.

${ }^{20}$ Even if, as Regan thinks, we must not use animals or humans (who have not consented) in research at all, there will still be some tragic circumstances outside the research setting-like Regan's own lifeboat cases-in which certain individuals who would be killed anyway may be killed so that not all will die (The Case for Animal Rights, pp. 286294). Even Regan implicitly accommodates the idea that there are differences in moral status; he just tightly restricts the kinds of cases where sacrifices are to be permitted.
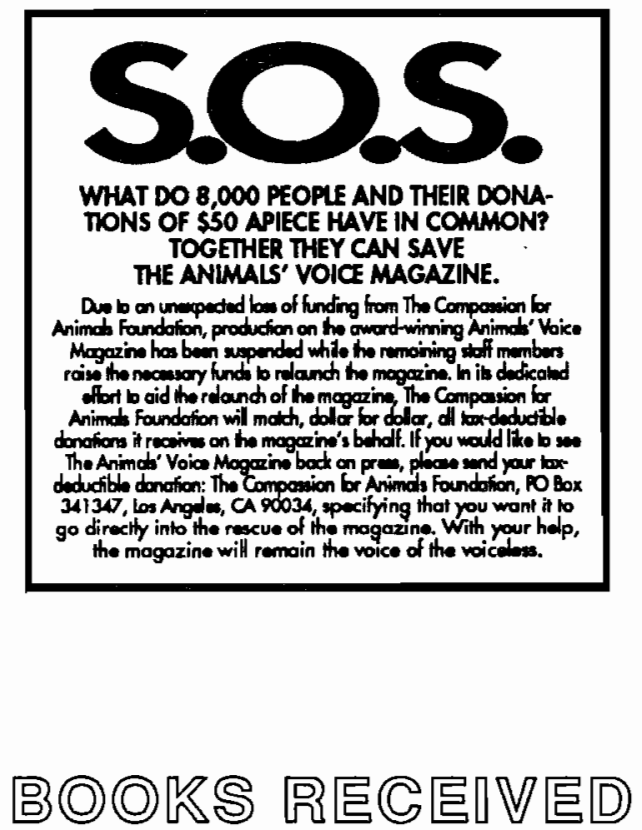

John J. Loeper

CRUSADE FOR KINDNESS

Henry Bergh and the ASPCA

New York: Atheneum, 1991

98p, bibliography, index

$\$ 12.95$ hardcover 